\title{
Reducing non-attendance rates for assessment at an eating disorders service: a quality improvement initiative
}

Article

Accepted Version

Jenkins, P. E. (2017) Reducing non-attendance rates for assessment at an eating disorders service: a quality improvement initiative. Community Mental Health Journal, 53 (7). pp. 878-882. ISSN 0010-3853 doi:

https://doi.org/10.1007/s10597-017-0118-7 Available at https://centaur.reading.ac.uk/76088/

It is advisable to refer to the publisher's version if you intend to cite from the work. See Guidance on citing.

To link to this article DOI: http://dx.doi.org/10.1007/s10597-017-0118-7

Publisher: Springer

All outputs in CentAUR are protected by Intellectual Property Rights law, including copyright law. Copyright and IPR is retained by the creators or other copyright holders. Terms and conditions for use of this material are defined in the End User Agreement.

www.reading.ac.uk/centaur 
Central Archive at the University of Reading

Reading's research outputs online 
1 Reducing Non-Attendance Rates for Assessment at an Eating Disorders Service: A Quality 2 Improvement Initiative

3 Running title: Non-attendance in eating disorders

$4 \quad$ Word count (Abstract): 173

5 Word count: 1,516

6

7

8

$9 \quad$ Keywords: eating disorders; partial booking; waiting lists; non-attendance; quality 10 improvement 


\section{Introduction}

Outpatient non-attendance (often referred to as Did Not Attend, or DNA) rates are a common problem within health services worldwide. The estimated cost to the UK National Health Service over a decade ago was $£ 65$ ( $\$ 100)$ per appointment, totalling $£ 300$ million ( $\$ 480$ million) in England alone,${ }^{1}$ and this figure is likely to have increased since ${ }^{2}$. There are other costs, too. Non-attendance results in under-utilisation of resources, can increase waiting times, and has been associated with poorer outcome (e.g., see $\left.{ }^{3}\right)$.

Although non-attendance is relatively well documented in general mental health, and much has been written about drop-out (or 'failure to engage') in eating disorders (EDs) treatment, very little information has been provided about non-attendance for initial assessments. This is particularly notable as DNA rates in EDs are amongst the highest of mental health specialities, alongside drug and alcohol services and community psychiatry, with rates particularly pronounced for initial appointments ${ }^{4}$. A study by Leavey et al. ${ }^{5}$ reported that 26 of 100 individuals referred to a large ED service in the UK failed to attend their first appointment. Similarly, in a study of a mental health and learning disability trust (approximate population of 1 million), Mitchell and Selmes ${ }^{4}$ reported DNA rates of $19.5 \%$ for the ED speciality (25/128 individuals offered initial appointments over a 1-year period) and, analysing care pathways across two large ED services in London, Waller et al. ${ }^{6}$ reported a non-attendance rate of $16.4 \%(n=260 / 1583)$ for initial appointments.

The costs of non-attendance are well known but, equally, the solutions also need to be costeffective. Given the associated burdens of non-attendance to organisations, staff, and patients, a number of interventions have been suggested, and found to improve attendance modestly (for reviews, see ${ }^{7-9}$ ). Waller et al. ${ }^{6}$ recommend direct patient contact (e.g., via telephone) when organising an initial appointment as well as the provision of written information, such as information sheets about the clinic. Some empirical support has been found for providing information ${ }^{10}$ and reminders ${ }^{11}$ in improving attendance, although other 
studies have failed to find such effects ${ }^{12}$. There may be different reasons for non-attendance across specialities (e.g., see ${ }^{5}$ ), and thus different procedures for reducing non-attendance may benefit different specialities. The use of 'partial booking' systems, which require patients to 'opt in' to appointments, has been shown to improve attendance rates ${ }^{13-16}$, although a recent systematic review ${ }^{8}$ did not generally support this finding. Within ED services, there is some evidence that 'opt-in' procedures can reduce waiting times for treatment and that subsequent non-attendance is not associated with levels of psychopathology or subjective well-being. Thus, such procedures are unlikely to decrease access for individuals who may report more severe pathology ${ }^{17}$ and may be helpful when booking initial appointments.

The current study reports on the effectiveness of an opt-in protocol in reducing DNA rates for initial appointments, using a quasi-experimental design to look at the impact of a change in service-level protocols on attendance rates. It was hypothesised that the new system, which emphasised patient choice in booking an appointment, would improve attendance (e.g., see $\left.{ }^{18}\right)$.

\section{Material and Methods}

\section{Setting}

The service is a specialist eating disorders service in the UK covering a population of around 700,000 adults. Outpatients are usually referred by a patient's general medical practitioner (GP), although referrals are accepted through other routes, such as the local Improving Access to Psychological Therapies (IAPT) service (see ${ }^{19}$ ), or general psychiatric services.

Prior to January 2013 , following receipt of a referral, patients were offered an appointment in writing to attend the unit for an assessment. Information about the service was included, and patients were asked to confirm their appointment. However, clinicians would often keep 
the appointment free even when no confirmation was given as many patients attended without confirming. Patients who did not attend were sent a letter asking them to reply within two weeks; if nothing was heard (in the absence of significant risk), they were discharged.

\section{Partial booking}

A partial booking system (e.g., ${ }^{14,16,20}$ ) was implemented in January 2013 , whereby patients are sent a letter asking them to contact the service to arrange an initial appointment. By doing so (usually by telephone), patients can arrange a more convenient date, time, and sometimes place (although there are constraints on these variables). As per the previous system, if there is no contact a further letter is sent, leading to discharge if no contact is made.

\section{Statistical analyses}

Data were analysed over a 20-month period before partial booking, and the ensuing 27 months. Non-attendance rates were used as the primary outcome, expressed as the percentage of DNAs of total appointments (i.e., Attendances + DNAs). The main effects of the intervention were assessed before and after, using the Mann-Whitney test (given unequal group sizes) and an a level of .05. Effect size estimates were obtained using point biserial correlation (r). Analyses were conducted with SPSS v22 and MS Excel.

The proposal was approved by the local NHS Quality and Audit Team and it was concluded that further ethics committee review was not required.

\section{Results}

Demographic data were available from April $2014(n=333)$; of this subset of the larger sample, $98.2 \%$ was female and mean age was 27.6 years $(S D=10.6)$. Due to the limited demographic data collected, it was not possible to conduct detailed analyses (e.g., whether certain demographic groups were disadvantaged by the change in procedure). 
Of 456 outpatient appointments offered between May 1, 2011 and December 31, 2012, 93 (20.4\%) were classified as DNA. The corresponding frequency was $15.1 \%(\mathrm{~N}=804)$ for the period of January 2013 to 1 April 2015 (see Figure 1). These figures were significantly different $(U=145.5, z=-2.679, p=0.007)$, with a medium effect size $(r=0.39)$. Odds ratio calculation showed that those in the historical group were 1.45 times more likely to DNA $(95 \% \mathrm{Cls}=1.07-1.95) . \mathrm{G}^{*}$ Power $3^{21}$ was used to conduct post hoc power analysis, using an observed effect size of 0.39 . This indicated that observed power $(1-\beta)$ of 0.99 exceeded the level recommended by Cohen ${ }^{22}$.

\section{Discussion}

The study found a similar DNA rate to other specialist ED units in the UK, a country with a publicly-funded health service. This rate was relatively high before the intervention, and non-attendance was reduced by using a partial booking system that offered patients greater agency regarding their initial appointment. This suggests that high DNA rates can be addressed in part by offering patients more choice around their appointments, in line with previous suggestions (e.g., ${ }^{14}$ ). Of note, the reduction of non-attendance in the current study was almost identical to that reported by Houghton et al. ${ }^{15}$, using a similar methodology including use of an opt-in letter in an NHS psychotherapy service.

Although partial booking appeared effective in reducing non-attendance, this system may still overlook some individuals and may also favour the more 'reachable' patient (e.g., $\left.{ }^{23}\right)$. Opt-in procedures have been found to be useful in managing treatment waiting lists in EDs, and do not discriminate sub-groups ${ }^{17}$; see also ${ }^{15}$. However, less is known about initial appointments, and the current study does not explore reasons for non-attendance; these may include resolution of problems, not agreeing that the referral was necessary ${ }^{4}$, or more 'negative' reasons, such as low motivation to change or negative views about treatment ${ }^{24}$. 
113 Anecdotally, we have found the partial booking system to be a positive change, reducing

114 DNA rates and being more patient-centred (see also ${ }^{13}$ ). Furthermore, using crude figures of approximately $£ 100$ per appointment ${ }^{2}$, a reduction from $20.4 \%$ to $15.1 \%$ might save the service over $£ 1600(\$ 2,560)$ per year, although some costs were not factored in to this analysis. Of note, in contrast to the study of Carmen et al. ${ }^{13}$, the number of individuals attending appointments did not decrease as a result of the opt-in procedure.

Aside from the lack of a randomised control group, which may have introduced selection bias, further shortcomings of this study were the limited demographic data collected and the lack of follow-up data. Previous studies have rarely reported demographic data, with some exceptions (see ${ }^{14}$ ), and so there remain significant gaps in the literature regarding the precise impact of opt-in procedures. Despite similarity with previous work (e.g., $\left.{ }^{15}\right)$, the generalisability of the findings here remains to be seen although the current study reports on a sample of routinely collected data and may thus be seen to have high ecological validity. Although the study spanned a period of nearly 4 years, there was no allowance for seasonal variation (e.g., see ${ }^{25}$ ) and no allowance was made for individual patients, some of whom may have been referred more than once in the study period. The use of a large number of individuals relative to previous studies with a clear intervention represents a strength of the study, particularly as few variables were explicitly manipulated (i.e., the general processes were only amended by changing how initial appointments are booked). However, reduction in non-attendance due to factors other than the intervention cannot be ruled out.

\section{Conclusions}

The intervention described above provides one of the first demonstrations of improving attendance at first assessment within a specialist eating disorders service, offering further evidence for the importance of flexibility and patient choice in reducing DNA rates (e.g., $\left.{ }^{15,26}\right)$. Attempts to improve patient care must consider all stages of the care pathway (see ${ }^{6}$ ), with addressing non-attendance being just one part. Further studies might seek to look in more 
139 detail regarding factors, such as demographic variables, that might be associated with non-

140 attendance and this has been lacking from previous studies. Although some work in ED

141 samples suggests that opt-in procedures do not disadvantage specific individuals ${ }^{27}$, this

142 could be furthered by looking at individuals who do not respond and investigating the

143 reasons why.

144

145 Disclosures and Acknowledgements: The author would like to thank all the staff involved

146 in supporting this project. The author reports no competing interests.

147 Funding:

148 This work was supported by resources and the use of facilities within X NHS Trust (removed

149 to preserve anonymity). 


\section{References}

1. Hull AM, Alexander DA, Morrison F, McKinnon JS: A waste of time: non-attendance at outpatient clinics in a Scottish NHS Trust. Health Bulletin 60:62-69, 2002

2. Reference Costs 2012-13. Department of Health, 2013. Retrieved online 1 August 2015 from https://www.gov.uk/government/uploads/system/uploads/attachment_data/file/26115 4/nhs_reference_costs_2012-13_acc.pdf

3. Bech M: The economics of non-attendance and the expected effect of charging a fine on non-attendees. Health Policy 74:181-191, 2005.

4. Mitchell AJ, Selmes T: A comparative survey of missed initial and follow-up appointments to psychiatric specialties in the United Kingdom. Psychiatric Services 58:868-871, 2007.

5. Leavey G, Vallianatou C, Johnson-Sabine E, et al: Psychosocial barriers to engagement with an eating disorders service: a qualitative analysis of failure to attend. Eating Disorders 19:425-440, 2011.

6. Waller G, Schmidt U, Treasure J, et al: Problems across care pathways in specialist eating adult disorder services. Psychiatric Bulletin 33:26-29, 2009.

7. Ambrose J, Beech B: Tackling non-attendance for outpatient appointments. Mental Health Practice 9:22-25, 2006.

8. Schauman O, Aschan LE, Arias N, et al: Interventions to increase initial appointment attendance in mental health services: a systematic review. Psychiatric Services 64:1249-1258, 2013

9. Stubbs N, Geraci SA, Stephenson PL, et al: Methods to reduce outpatient nonattendance. American Journal of the Medical Sciences 344:211-219, 2012

10. Hardy KJ, O'Brien SV, Furlong NJ: Information given to patients before appointments and its effect on non-attendance rate. British Medical Journal 323: 1298-1300, 2001. 
11. Guy R, Hocking J, Wand H, et al: How effective are Short Message Service reminders at increasing clinic attendance? A meta-analysis and systematic review. Health Services Research 47:614-632, 2012

12. Clough BA, Casey LM: Using SMS reminders in psychology clinics: a cautionary tale. Behavioural and Cognitive Psychotherapy 42:257-268, 2014

13. Carmen D, Shah S, Gilbert S, Russell F: Improving attendance at an eating disorders clinic by means of an 'opt-in' letter. Clinical Psychology Forum 173:22-25, 2007

14. Hawker DSJ: Increasing initial attendance at mental health outpatient clinics: opt-in systems and other interventions. Psychiatric Bulletin 31:179-182, 2007

15. Houghton S, Saxon D, Smallwood A: Effects of opt-in letters in a National Health Service psychotherapy service. The Psychiatrist 34:507-510, 2010

16. Kenwright M, Marks IM: Improving first attendance for cognitive behaviour therapy by a partial booking appointment method: two randomised controlled trials. Journal of Mental Health 12:385-392, 2003

17. Jenkins PE, Turner $\mathrm{H}$, Morton L: Active waiting list management: potential usefulness in a community eating disorders service. Eating Disorders 22:72-81, 2014

18. McLean S, Gee M, Booth A, et al: Targeting the use of reminders and notifications for uptake by populations (TURNUP): a systematic review and evidence synthesis. Health Services and Delivery Research 2:34, 2014

19. Clark DM: Implementing NICE guidelines for the psychological treatment of depression and anxiety disorders: the IAPT experience. International Review of Psychiatry 23:318-327, 2011

20. Milne RG: Reducing non-attendance at specialist clinics: an evaluation of the effectiveness and cost of patient-focussed booking and SMS reminders at a Scottish health board. International Journal of Consumer Studies 34:570-580, 2010 
21. Faul F, Erdfelder E, Lang A-G, Buchner A: G*Power 3: a flexible statistical power analysis program for the social, behavioral, and biomedical sciences. Behavior Research Methods 39:175-191, 2007

22. Cohen J: Statistical power analysis for the behavioral sciences, $2^{\text {nd }}$ edition. Hillsdale, NJ, Lawrence Erlbaum, 1988

23. Henry LA, Ball S, Williams RM: A study of attendance and filling in of preappointment questionnaires in an outpatient clinical psychology service. Journal of Mental Health 7:411-424, 1998

24. Mahon J: Dropping out from psychological treatment for eating disorders: what are the issues? European Eating Disorders Review 8:198-216, 2000

25. Chew KSY, McCleary R: The Spring peak in suicides: a cross-national analysis. Social Science \& Medicine 40:223-230, 1995

26. Sharp DJ, Hamilton W: Non-attendance at general practices and outpatient clinics: local systems are needed to address local problems. British Medical Journal 323:1081-1082, 2001

27. Tatham M, Stringer H, Perera S, Waller G: "Do you still want to be seen?": the pros and cons of active waiting list management. International Journal of Eating Disorders 45: 57-62, 2012 
224 Figure 1. Rates of non-attendance (\%) over the course of the study.

225 